\title{
Comparative Study of English Learning Beliefs between Chinese and Korean College Students in Minority Region
}

\author{
Haiying Yan $^{1}$ \\ ${ }^{1}$ College of Foreign Languages, Yanbian University, No.977, Park Road Yanji City, Jilin Prov. China. \\ Correspondence: Haiying Yan, College of Foreign Languages, Yanbian University, No.977, Park Road Yanji City, \\ Jilin Prov. China.
}

Received: November 30, 2019

Accepted: January 16, 2020

Online Published: January 17, 2020

doi: 10.5539/elt.v13n2p97

URL: https://doi.org/10.5539/elt.v13n2p97

\begin{abstract}
Beliefs are a central construct in every discipline. Meanwhile, students' beliefs about language learning play an important role in their language motivation, attitude and achievement. This study intends to explore the current situation of the English learning beliefs of College students in Minority Regions in China and then attempts to find out the similarities and differences in English learning beliefs between Chinese and Korean students. The results show that self-efficacy is the most important factor affecting non-English major sophomores of minority regions. And there are clear differences exist between two sub-scales of English learning beliefs.
\end{abstract}

Keywords: English learning beliefs, minority regions, self-efficacy

\section{Introduction}

Beliefs are considered one area of individual learner differences that may influence the processes and outcomes of second/foreign language learning. Beliefs are a central construct in every discipline that deals with human behavior and learning (Bernat and Bvozdenko, 2005). As for the cause of learners' belief, researches find out some beliefs are influenced by students' previous(positive or negative ) experiences as language learners, while other beliefs are shaped by students' cultural background, family/home background(Horwits,1987), and individual differences such as personality(Langston and Sykes,1997; Abraham and Vann,1987). They may have a profound influence on learning behavior (Yang, 1999; Cotterall, 1995), and may directly influence or even determine a learner's attitude and motivation when learning the language (Riley,1996). Students' beliefs about language learning do play an important role in influencing their motivation, attitude, motivational intensity, strategy use, anxiety and language achievement (Banya and Cheng 1997). The academic research on the beliefs of learning also shows that learners' beliefs of language may directly affect or even determine their attitude, motivation or behavior when learning a language (Liu,Y.J. 2010). For ethnic minority college students, English is the third language, and their learning process is influenced by their mother tongue, Chinese and their own culture in Minority regions in China. As one of the intrinsic psychological factors, learners' beliefs have an important impact on the process and the outcome of foreign language learning. Many years of language teaching experience in minority region told that some Korean students hold pessimistic and negative beliefs about English learning. Therefore, it is an urgent problem for colleges and universities in ethnic minority areas to help students set up correct language learning beliefs. This study examines non-English major college students' English learning beliefs (ELB) and then makes a comparison between Chinese and Korean students so that to further infer that whether there are differences in ELB of different nationalities in minority areas. Through analyzing the differences, more effective measures can be taken to perfect the curriculum of English teaching, change teaching strategies toward minority students and arouse learners' interest especially Korean students' self-efficacy in English learning in China.

\section{Relevant Literature}

\subsection{Research Abroad}

Since the 1970s, the focus of language teaching research has gradually shifted from the object of teaching to the subject learners of teaching. As one of the main psychological factors, learner beliefs have become a hot topic in the field of second language acquisition in recent years. Since Horwitz (1987) put forward the concept of learning belief, the research on learning belief has attracted much attention. According to Wenden (1986), 
metacognitive knowledge makes up learners' belief; Yang's (1985) research results show that learners' self-efficacy concepts are highly correlated with the types of learning strategies. Wenden said that "belief in the best learning method" can affect second language learning. Howitz (1987) also believes that learners' belief has an impact on the operation of human learning systems in second language learning. Linguists study foreign language learning concepts from different perspectives, so they have different definitions of foreign language learning concepts. Wenden (1986), Horwitz (1988), Wesely (2012) and other scholars researched from the perspective of students' metacognitive beliefs and strategies, the nature of language learning, culture and other perspectives, believe that the English language learning beliefs have a profound impact on language learning. Horwitz (1988) designed the famous Language Learning Inventory (BALLI) to measure students' language learning beliefs in five factors, including the difficulty of language learning, foreign language aptitude, the nature of language learning, learning and communication strategies, and motivation and expectation.

\subsection{Research at Home}

At the end of the last century, Chinese scholars represented by Wen Qiufang(1996) carried out an empirical study on the English learning beliefs and learning strategies of non-English majors, which confirmed the correlation between CET-4 scores and learning strategies. They also defined and categorized the foreign language learning beliefs of non-English majors. They believed that English learners' beliefs were related to their learning beliefs. ELB refers to a system of views formed by college students through their own experience or influenced by others in the process of learning English, which has a certain degree of stability. This concept has a subtle and far-reaching impact on students' English learning. As a result, research reveals that attitudes toward learning and the perceptions and beliefs that determine them may have a profound influence on learning behavior(Bandura and Schunk,1981; Cotterall,1995) and on learning outcomes (van Rossum and Schenk,1984). They are also central to the learner's overall experience and achievements (Ryan, 1984Sakui and Gaies,1999; Schommer,1990)

At present, the research on language learners' beliefs in China mainly focuses on college students' English learners, such as Dai Weidong and Wang Dong (2002), conducted a survey and analyze language learning beliefs of English majors, Li Kun (2006) studied on learners' beliefs and learning strategies, and Li Zhewei (2007) explored on ELB of non-English majors. However, there are few studies on the English language learning beliefs of minority areas.

\section{Methodology}

\subsection{Research Questions are as Follows:}

(1) What is the current situation of ELB of non-English major sophomores in minority region University?

(2) Are there any significant differences in ELB between different nationalities?

\subsection{Participants}

The research was carried out at the non-English majored sophomores at Yanbian University, China. The subjects selected for this study have been studying English almost(Data collected just before the final examination) two years in University, and completed the two-year compulsory English course at University. The ELB has had a certain impact on students' language learning motivation, attitude and achievements. A total of 329 non-English major second -year undergraduate students were involved in this study, and 29 of them were excluded due to data missing. The valid number at last is 300 , including 101 Korean students, 169 Chinese students and 30 other minority students, 89 male students and 211 females.

\subsection{Research Instruments}

The researcher decided to utilize a questionnaire which is known to be one of the most useful tools to exploit the subjects' attitude, beliefs and perceptions. The 26-item questionnaire consisted of five dimensions including English learning self-efficacy beliefs, English learning focus, the nature of English learning, language learning instrumental and integrative motivation. The framework of ELB is based on the BALLI designed by Horwitz. BALLI is widely used in the field of language acquisition because of its high reliability and validity. BALLI measures learners' beliefs through empirical and quantitative means. The items were rated on a five-point Liker-scale, including "totally disagree", "disagree", " uncertain ", "agree" and "totally agree". Their corresponding values are 1,2,3,4,5, respectively. The questionnaire was reliable as proven by its internal consistency indexes. As evidenced in Table 1 below, the Cronbach's Alpha was greater than .700.

\subsection{Data Collection and Analysis}

The questionnaire copies which had been translated into Chinese beforehand were delivered to 329students.On receipt of questionnaires from the respondents, 300 copies $(91.2 \%)$ were valid. Then the data were analyzed 
using the Spss17 for windows versions. Factor analysis was used to analyze the current situation ELB of none-English majored sophomore students in minority University and Independent sample t-test analysis was employed to compare ELB between Chinese and Korean students.

\section{Results and Analysis}

\subsection{Factor Analysis of ELB}

Table 1 shows that the questionnaire is suitable for factor analysis $(\mathrm{KMO}=0.704$; Bartlett's star test results are significant). It shows that the variables are not independent, they have common factors and are suitable for factor analysis. Fourteen items were retained after orthogonal rotation using the maximum variance method (Varimax). Five factors were classified naturally, and $63.457 \%$ of the total variance was explained accumulatively.

Table 1. Examination of KMO and Bartlett

\begin{tabular}{ccc}
\hline Kaiser-Meyer-Olkin & .704 \\
\hline Bartlett's Test of Sphericity & Approximate Chi-Square & 1240.474 \\
& Degree of freedom & 190 \\
& Significance & .000 \\
\hline
\end{tabular}

Table 2 shows that the reliability coefficients of the five influencing factors are between 0.569 and 0.703 , and the internal consistency is acceptable. Table 3 shows the influencing factors and a load of variables. According to the specific content of each factor item (DÖRNYER Z. 2001), five factors are named as self-efficacy belief, English learning focus, English learning instrumental motivation, the nature of English learning and English learning integrative motivation. English learning focus factor includes three variables, of which the seventh item is more important than the other two. The result shows that the second-year students of minority regions still think that grammar is more important than vocabulary and translation in learning English. The high factor loading $(0.844)$ of twentieth item(learn English for experiencing the culture of English-speaking countries) shows that students who have spent nearly two years of college life in Yanbian area, where minority cultures and mainstream cultures are highly integrated, have been able to combine foreign languages studying with experiencing foreign language cultures.

Table 2. Factor, Eigen Values, Total Variance Explanation, Reliability Coefficient and Mean

\begin{tabular}{ccccc}
\hline Factor & Eigen Value & $\begin{array}{c}\text { Total Variance } \\
\text { Explanation \% }\end{array}$ & $\begin{array}{c}\text { Reliability } \\
\text { Coefficient }\end{array}$ & Mean \\
\hline Self-efficacy & 3.020 & 18.877 & .688 & 2.9344 \\
English Learning Focus & 2.015 & 12.596 & .672 & 3.3955 \\
Instrumental & 1.714 & 10.712 & .569 & 3.5555 \\
$\quad$ Motivation & & & .581 & 4.2133 \\
Nature of English & 1.442 & 9.012 & & \\
$\quad$ Learning & & & .703 & 3.1266 \\
Integrative Motivation & 1.134 & 7.090 & & \\
\hline
\end{tabular}


Table 3. Loading Factors of Variables

\begin{tabular}{|c|c|c|c|c|c|}
\hline \multirow[t]{2}{*}{ Items } & \multicolumn{5}{|c|}{ Loading Factors of Five Dimensions } \\
\hline & Factor1 & Factor2 & Factor3 & Factor4 & Factor 5 \\
\hline & Self-efficacy & $\begin{array}{c}\text { English } \\
\text { Learning } \\
\text { Focus }\end{array}$ & $\begin{array}{c}\text { Instrumental } \\
\text { Motivation }\end{array}$ & $\begin{array}{c}\text { Nature of } \\
\text { English } \\
\text { Learning }\end{array}$ & $\begin{array}{l}\text { Integrative } \\
\text { Motivation }\end{array}$ \\
\hline
\end{tabular}

1. English is a difficult language

3. I have a special ability for learning English

5. I believe that I will learn to

speak English well

7. The most important part of

learning English is learning the

grammar

8. The most important part of

learning English is learning vocabulary words

9. The most important part of learning English is learning how to translate from the native language 14. I learn English for passing the exam

17. If I learn English very well, I will have better opportunities for a

$$
\text { good job }
$$

18. Learning English well will gain respect and a sense of achievement

10. It is best to learn English in an

English-speaking country

12. It is important to repeat and

$$
\text { practice a lot }
$$

13. It is important to speak English with an excellent pronunciation

19. I would like to learn English so that I can read and see the film in

$$
\text { English }
$$

20. I learn English for experiencing the culture of English-speaking countries

\section{.787}

.637

.822

.808
.833

.822

.441

Factor 1 to factor 5 is the order of factors obtained by factor analysis, which shows the influencing degree of each factor. The result shows that the self-efficacy factor has the greatest impact. The second influencing factor is the English Learning Focus. The result shows that non-English major students in Minority areas believe that learning grammar, vocabulary, translation is still the most basic part of learning English. The specific reason is that college students in China have a heavy task of learning English after they enter universities. College 
students still face CET4 (College English Test Band 4) and CET6(College English Test Band 6) examinations. After entering universities, they are still making up for English grammar and vocabulary, thus not have enough time to enjoy different cultures or knowledge brought about by learning English.

\subsection{Descriptive Analysis of ELB}

To further understand the current situation of college students' ELB in minority regions, the author made a descriptive analysis of five factors of ELB. The results are shown as Table 2, the mean value of the fourth factor, the nature of English learning has the highest mean value that is 4.2133 , followed by the third factor, instrumental motivation factor is 3.5555 , and the lowest mean value is self-efficacy factor is 2.93443 ; For nature of English learning factor, $90.3 \%$ and $82 \%$ of the subjects chose to agree or totally agree with the Item 12 that is "It is important to repeat and practice a lot". Among the instrumental motivation factor, $70.3 \%$ of the subjects agree that learning English well will help to have better opportunities for a good job, which shows that students are well aware that under the influence of economic globalization, learning English well is one of the necessary skills to find a job. In the first item of the self-efficacy belief, 52.7\% of the students thought that English was a very difficult or difficult language, indicating that although they had studied English for more than ten years, students still believe that English is a time-consuming and laborious subject; while in the fifth item, Only 10.3\% of the students disagreed and totally disagreed that they can learn English well. The result recommends that while students admit that English is a difficult subject, they are still confident in learning to speak English well.

\subsection{Independent Sample T-test}

There 300 undergraduate sophomore students are participating in this test, including 101 Korean students and 169 Chinese and 30 other ethnic minority students. To explore the differences of ELB between Chinese and Korean non-English major sophomores' in minority areas, we ignored the ELB of 30 other ethnic minority students in this comparison. The 101Korean and 169 Chinese students were involved and the data is shown as Table 4. From the result, we can see the differences between Chinese and Korean students' ELB in dimensions of self-efficacy and the nature of English learning. The independent sample T-test result shows that there is a significant difference in self-efficacy $(\mathrm{P}=.000<0.05)$, indicating that the self-efficacy of Korean students is weaker than Chinese students. One of the reasons is that Chinese students graduated from Chinese middle school, while $47.5 \%$ of Korean students come from Korean middle school for those who have experienced great differences in language and culture in the post-university transitional period and may meet more difficulties that will affect the self-efficacy of English learning. Mean values of self-efficacy among different nationalities were further compared. The results show that the mean value of self-efficacy of Korean students is 2.6533 while the mean value of self-efficacy of 48 students came from the Korean middle school examiners is only 2.5764 . Self-efficacy dimension includes the following three items: the first item is "English is a difficult language" the third item is "I have a special ability for learning English" and the fifth item is "I believe that I will learn to speak English well". The bigger the mean value is, the stronger the confidence students have in ELB. The results show that Korean students have less confidence in learning English than Chinese students.

Regarding English learning focus, instrumental motivation and integrative motivation, it shows no significant difference in analysis and evaluation between Korean and Chinese student $(\mathrm{P}=.245, .731, .891>0.05)$.which means that they share the same level of analysis and evaluation and there is no ethnic distinction in learning motivation among college students.

However we found that there is a significant difference between Chinese and Korean students' ELB in the nature of English learning, $(\mathrm{P}=.000<0.05)$. Through the comparison of the mean values, it is found that Korean college students' mean value $(4.0792,4.1782,3.8713)$ is lower than that of Chinese students $(4.2604,4.4793,4.1479)$ in all the three items (Item10, Item12, Item13). Item 10 is "it is best to learn English in the country where English is their mother tongue". The results show that Korean college students pay less attention to the English learning environment than Chinese college students. 
Table 4. Independent sample T-test

\begin{tabular}{|c|c|c|c|c|c|c|}
\hline \multirow[t]{2}{*}{ Variables } & \multirow{2}{*}{$\begin{array}{c}\text { Korean } \\
\mathrm{M}\end{array}$} & \multicolumn{3}{|c|}{ Chinese } & \multirow[t]{2}{*}{$t$} & \multirow[t]{2}{*}{ Sig (2-tailed) } \\
\hline & & SD & $\mathrm{M}$ & SD & & \\
\hline $\mathrm{N}$ & 101 & & 169 & & & \\
\hline Self-efficacy & 2.6533 & .65678 & 3.0456 & .70676 & -4.531 & .000 \\
\hline English Learning Focus & 3.4817 & .64710 & 3.3886 & .62881 & 1.164 & .245 \\
\hline Instrumental Motivation & 3.5310 & .57565 & 3.5562 & .58629 & -.344 & .731 \\
\hline Nature of English learning & 4.0427 & .57321 & 4.2961 & .52152 & -3.722 & .000 \\
\hline Integrative Motivation & 3.0941 & .78649 & 3.0799 & .84223 & .137 & .891 \\
\hline
\end{tabular}

\section{Conclusions and Discussion}

According to the detailed analysis above, we can draw the following conclusions:

Non-English majors in minority areas of China have a variety of ELB, among the five dimensions of ELB, self-efficacy has the greatest influence.

There are significant differences in self-efficacy beliefs and the nature of English learning between Korean and Chinese college students in minority areas.

There are no significant differences in English learning focus, instrumental motivation, and integrative motivation between Korean and Chinese college students in minority areas.

There are significant differences in the nature of English learning of ELB between Korean and Chinese college students in minority areas.

Then we'll discuss these findings.

(1) The main reasons why Korean students have lower self-efficacy may be as follows:

Firstly, as a comprehensive university for ethnic minorities in the border areas of China, Yanbian University has lowered the entrance admission scores of ethnic minorities, resulting in English Entrance scores of Korean students is relatively low. (the average English entrance scores of Korean students are 101.42; the average entrance English scores of Chinese students are 112.90).For some Korean students, especially for the students who graduated from Korean middle school who are permitted to answer the entrance exam in Korean, English proficiency is even worse (the average entrance English score of 48 subjects is only 97.35). Secondly, some Korean students were taught in Korean in middle school while all subjects are taught in Chinese after entering the university, with the change of English learning cultural and language environment, many Korean students can not adapt to it when they first enter the university. When they encounter difficulties and setbacks in English learning, they are prone to psychological problems such as anxiety, inferiority and depression (DÖRNYER Z.2001) which lead to fear of learning English and ultimately affect English learning performance and their self-efficacy. Thirdly, for Korean students English learning is the third language acquisition, which is quite different from that of Han Chinese students; The phenomenon of negative cultural transfer will affect minority college students' English learning more; The mode of thinking in the process of learning, together with the mother tongue learning experience of the national language, will interfere with ethnic minority students ' ELB to a certain extent.

(2) This study shows that no significant differences exist in English learning focus, instrumental motivation and integrative motivation of ELB between Korean and Chinese students. The result in factor analysis shows that English learning focus rated the second influencing factor among all the five dimensions of ELB indicated that students in minority areas have a narrow understanding of the focus of English learning, they believe that grammar, vocabulary and translation are still important factors affecting English learning beliefs; Grammar and vocabulary learning is the focus of traditional English teaching, and it is also the assessment criterion of English proficiency in college and it will inevitably affect students' cognition of English Learning, the mean value of Korean students' beliefs about learning focus is 3.4817 much higher than that of Chinese students 3.3886 means that Korean students pay even more attention to English grammar, vocabulary than Chinese students. This narrow and one-sided concept is also directly reflected in the influence of English learning motivation, students believe that passing examination is an important reason for English learning. Most of the students ( For Item 17 agree and strongly agree students account for $70.3 \%$ of the total number of subjects) had a single motivation, indicating that the motivation of non-English majors in Yanbian University came mainly from instrumental 
motivation(the use of target language as a tool to achieve specific goals, achievements, information media, personal development)(Gao,2003), while according to Gao's(2013) research results, their intrinsic interest, such as happiness, enjoy learning English itself, like movies and songs are the most important factors affecting English learning motivation. The results of Li Zhewei's(2007)survey of non-English majors show that the difference in learning motivation between CET high-group and low-group students is that high-group students tend to have the comprehensive motivation (integrated motivation) while low-group students tend to have instrumental motivation. However, the result of this study shows differently from the above research that the instrumental motivation rated higher than integrative motivation for the students of Yanbian University. It may indicate that learning motivation for most non-English majors in minority areas should be stimulated or aroused as integrative motivation, instrumental motivation may contribute to their English learning, but it may lose interest in learning English or reduce the time spent in English learning; affect their English achievement or sense of achievement, and ultimately reduce their sense of self-efficacy in learning English. Therefore, English teachers should actively cultivate students' interest in English learning, fully mobilize students' potential learning needs, and improve students' confidence in English learning.

(3) The fourth dimension, the nature of English learning of non-English majors' ELB at Yanbian University, has the highest mean value 4.2133. It shows that students attach great importance to English pronunciation. They believe that excellent pronunciation is very important and English proficiency can be improved through repeated practice. However, with the comparing results, significant differences exist between Korean students and Chinese students. Korean students have a lower mean value than Chinese Students. One of the reasons is that most Korean students lived in the bilingual environment in a minority area of China, they can speak and communicate with bilingual language freely and they know that pronunciation will not affect too much when communicating.

The study on ELB of non-English majors in minority regions in China also has some implications for teaching.

(1) English teachers in minority areas should actively cultivate students' interest in English learning, fully mobilize students' potential learning needs, and improve students' confidence in English learning, especially for the ethnic minority students. It suggests that in the process of English teaching, especially for the college teachers of multinational regions, should guide students correctly deal with pronunciation problems, encourage students to use English to communicate, experience English culture and master effective learning strategies. It requires English teachers to encourage students to develop positive attitudes and concepts in language learning while imparting subject knowledge and skills.

(2) As an English teacher of ethnic minority university, we should help ethnic minority students understand their weakness and strengths in English learning process, then formulate practical and individualized learning programs; consciously improve teaching methods and adopt different strategies for different nationality to increase their sense of achievement in English learning; stimulate ethnic minority students' enthusiasm and motivation for English learning; constantly enhance their interest and confidence in English learning and ultimately improve their sense of self-efficacy in English learning.

\section{Summary}

This study investigates the ELB of non-English majors in minority regions of China through questionnaires. The result shows that self-efficacy, the focus of English learning, instrumental motivation, the nature of English learning and the motivation of integration affect the ELB of non-English majors at Yanbian University. ELB is dynamic and diverse(Cui, G. and Liu, X.M.2013), and also plays a very important role in English learning. Although correct beliefs and concepts may not necessarily guarantee the success of learning, they can guide students to use their resources to increase the possibility of learning success. Horwitz (1987) believes that learners' beliefs are easily influenced by teachers, so teachers should help students develop a positive attitude by showing them what kind of beliefs they have is a mismatch with the principle of classroom instruction. Furthermore, teachers can help them to use strategies that good language learners frequently use, or suggest some strategies which may match their personality or learning styles (Banya and Cheng,1997). Teachers should realize what is the most influential factor of ELB of non-English majors and guide students to understand the wrong concepts that hinder English learning, then help them learn English effectively. For some universities of ethnic minority regions, due to the influence of national preference educating policy, a certain proportion of minority students have been enrolled inevitably, therefore, the minority students' self-efficacy will be affected by their lower achievement in English learning. For the low-level group of English learners think that learning English well depends on the role of Englis teachers(Song, T.H.2014). As an English teacher of minority regions, we should help ethnic minority students adapt to the new language environment as soon as possible, also 
help them get over the negative cultural transfer affecting their ELB and then improve their sense of self-efficacy in English learning.

The deficiencies of this study are that the sample collection is limited to non-English majors of sophomores at Yanbian University. Future research may be made to collect more data from other ethnic minority areas. Besides, due to the limited conditions, the comparative study of ELB is only conducted in two ethnic minority students, Korean and Chinese students, hoping to attract more attention from English teachers and further study on students' beliefs in other ethnic minority areas. The validity of the conclusions of this study needs to be further verified in future teaching and research.

\section{References}

Abraham, R.G. \& Vann, R.J. (1987). Strategies of two language learners: a case study.In A.L.Wenden and J.Rubin (eds.).Learner strategies in language learning.London: Prentice-Hall.

Bandura, A. \& Schunk, D. (1981). Cultivating comepetence, self-efficacy, and intrinsic interest through proximal self-motivation. Journal of Personality and Social Psychology, 41, 586-598

Banya, K. \& Cheng, M.H. (1997). Beliefs about foreign language learning: a study of beliefs of teachers' and students' cross cultural settings. ERIC Document Reproduction Service, ED411691.

Bernat, E. \& Gvozdenko, I. (2005). Beliefs about language learning: current knowledge, pedagogical implications, and new research directions. TESL-EJ9, 1-21

Cotterall, S. (1995). Readiness for autonomy: investigating learner beliefs. System, 23, 195-205

Cui, G \& Liu, X.M. (2013). A New Phase of Studies on Language Learners' Individual Differences. Foreign Languages in China, 04, 61-66. https://doi.org/10.13564/j.cnki.issn.1672-9382.2013.04.008

Dai, W.D. \& Wang, D. (2002). An Investigation and Analysis of Language Learning Concepts of English Majors 5. Foreign Language World, 5, 24-29

DÖRNYER Z. (2001). Teaching and researching motivation London: Longman

Gao, Y. \& Liu, H.G. (2014). An Empirical Study of Second Language Motivation Control Strategies for Non-English Majors. Journal of PLA University of Foreign Languages, 3, 33-42

Gao, Y.H., Zhao, Y., Cheng, Y. \& Zhou, Y. (2003). Motivation Types of Chinese College Undergraduates. Modern Foreign Languages, 1, 28-38

Horwitz, E. K. (1987). Surveying student beliefs about language learning. Learner strategies in language learning, 110-129.

Langston, C.A. \& Skykes, W.E. (1997). Beliefs and the big five: cognitive bases of broad individual differences in personality. Journal of Research in Personality, 141-165

Li, K. (2006). The Relationship Between Learners' EFL Belief and Strategies(master thesis): Southwest University, China.

Li, Z.W. (2007). A Survey of English Learning Concepts of Non-English Major College Students. Foreign Language Education, 5, 49-54

Liu, Y.J. (2010). A quantitative study and analysis of the relationship among College English learners' learning concepts, self-efficacy and learning strategies. Foreign languages in China, 7, 65-70. https://doi.org/10.16362/j.cnki.cn61-1023/h.2010.04.021

Ryan, M.P. (1984). Monitoring text comprehension: Individual differences in epistemological standards. Journal of Educational Psychology, 73, 1226-1238

Sakui, K. \& Gaies, S.J. (1999). Investigating Japanese learners' beliefs about language learning. System, 27(99), 473-492

Schommer, M.A. (1990). Effects of beliefs about the nature of knowledge and comprehension. Journal of Educational Psychology, 82, 498-504

Song, T.H. (2014). Comparative Study on EFL and ESL Learners from the Perspective of Constructivism Theory. Chinese foreign language, 11, 75-81. https://doi.org/10.13564/j.cnki.issn.1672-9382.2014.04.011

Statistical Bulletin on National Economic and Social Development of Yanbian Korean Autonomous Prefecture in 2017.Retrieved from http://www.crei.cn

Van Rossum, E.J. \& Schenk, S.M. (1984). The relationship between learning conception, study strategy and 
learning outcomes. British Journal of Educational Psychology, 54, 73-83

Wen, Q.F. \& Wang, H.X (1996). The relationship of learner variables to scores on College English Test-Band 4. Foreign Language Teaching and Research, 4, 33-394

Wenden AL. (1986). Helping language learners think about learning. English Language Journal, 40, 3-12

Wesely, P. M. (2012). Learner Attitudes, Perceptions, and Beliefs in Language Learning. Foreign Language Annals, 45, 98-117. https://doi.org/10.1111/j.1944-9720.2012.01181.x

Yang, J.P. \& Chen C. (2016). SEM Research on English Learning Metacognitive Person Knowledge for Ethnic Preparatory Students of Inland Classes. Journal of Beijing University of Posts and Telecommunications, 10, 109-116

Yang N. D. (1999). The relationship between EFL learners' beliefs and learning strategy use. System, 27, 515-535.

Zhou, F.L. \& Lin,Y.W. (2019). A Comparative Study of Critical Thinking Skills Between English and Japanese Majors in a Normal University. English Language Teaching, 12, 30-38, https://doi.org/10.5539/elt.v12n12p30

\section{Copyrights}

Copyright for this article is retained by the author(s), with first publication rights granted to the journal.

This is an open-access article distributed under the terms and conditions of the Creative Commons Attribution license (http://creativecommons.org/licenses/by/4.0/). 